\title{
Predicting Turning Points in the South African Economy
}

\section{Elna Moolman}

Department of Economics, University of Pretoria

\begin{abstract}
Despite the existence of macroeconomic models and complex business cycle indicators, it would be beneficial to policymakers and market participants if they could look at one well-chosen indicator in predicting business cycle turning points. If one indicator accurately predicts business cycle turning points, it provides an easy way to confirm the predictions of macroeconomic models, or it can eliminate the need for a macroeconomic model if the interest is in the turning points and not in the levels of the business cycle. The objective of this paper is to investigate whether turning points of the South African business cycle can be predicted with only one economic indicator.

JEL E32, 37
\end{abstract}

\section{INTRODUCTION}

The modern literature on business cycles dates back to the seminal work of Burns and Mitchell (1946). They defined the business cycle as follows: "a cycle consists of expansions occurring at about the same time in many economic activities, followed by similarly general recessions, contractions and revivals that merge into the expansion phase of the next cycle: this sequence of change is recurrent but not periodic" (Burns and Mitchell, 1946: 3). This definition remains the basis of business cycle analysis, and specifically, it is the foundation of several recent studies that model the characteristics that distinguish expansions from contractions.

This study will model the two features of the Burns and Mitchell definition, namely the occurrence of expansions and contractions, and the common movements of each of the two phases with certain economic indicators. Specifically, the relationship between the turning points of the business cycle and several individual leading indicators will be modeled. Accurate predictions of business cycle turning points will help investors to increase profits by knowing when asset prices will reach a maximum or minimum (based on the relationship between the asset's price and the business cycle), producers can 
improve their inventory planning and if the selected leading indicator is a policy variable it will assist policy-makers in understanding the time lag with which policy affects the real economy.

Despite the existence of macroeconomic models and composite indices of leading business cycle indicators, policymakers and market participants can benefit significantly if it is possible to look at only a single indicator such as the stock exchange or an interest rate in predicting business cycle turning points. If a single indicator can accurately predict business cycle turning points, it provides a quick and easy way to confirm the predictions of macroeconomic models, or if the economic agent is only interested in the turning point and not the level of the business cycle, he doesn't need a macroeconomic model but can simply use this indicator. The objective of this paper is not to model or predict the level of the business cycle, but rather to select the best single leading indicator for predicting turning points in the business cycle.

The study is organized as follows: The next section gives a brief overview of the relevant literature. Section 3 describes the econometric technique and section 4 describes the leading indicators used in the empirical analysis. Section 5 presents the results of the empirical analysis, while section 6 provides the conclusion.

\section{LITERATURE REVIEW}

Estrella and Mishkin (1998) compared the performance of various financial variables, including four term structures of interest rates, stock prices, monetary aggregates, indices of leading indicators and other economic variables such as GDP, CPI and exchange rates, as predictors of US recessions. They estimated probit models with quarterly data for the period 1959 to 1995, and evaluated the performance of the leading indicators by using the pseudo- $\mathrm{R}^{2}$ value developed for dichotonomous models by Estrella (1998). Their results indicated that the interest rate spread outperforms the other indicators for forecasting beyond one quarter ahead. They also tested the performance of all the possible models that includes both the interest rate spread and one other indicator as explanatory variables.

Several studies confirmed the result of Estrella and Mishkin (1998) that the interest rate spread is successful with predicting business cycle turning points. Estrella and Hardouvelis (1991) were the first to empirically analyze the term structure as a predictor of real economic activity. Regressions of future GNP growth on the slope of the yield curve and other information variables showed that a steeper (flatter) slope implies faster (slower) future growth in real output. 
The forecasting accuracy in predicting cumulative changes is highest 5 to 7 quarters ahead. In addition, they also used a probit model to analyze the predictive power of the term structure on a binary variable that simply indicates the presence or absence of a recession.

Bernard and Gerlach (1996) tested the ability of both the domestic and foreign term structures to predict business cycle turning points in eight industrial countries for the period 1972 to 1993 . Using probit models, they show that the domestic term spreads are statistically significant in explaining business cycle turning points in all eight countries. The period over which the domestic term spread successfully forecasts the turning points vary across countries, but the optimal forecast period ranges from two to five quarters. Nel (1996) studied the relationship between the term structure of interest rates and the South African business cycle. He found that they were cointegrated, in other words a contemporaneous relationship exists, despite a poor overall fit.

Cook and Smith (2001) assessed the effectiveness of transplanting a forecasting method based on a probabilistic approach in the South African context. They tested the ability of some of the components of the composite index of leading indicators to predict both the official Reserve Bank turning points as well as the mechanistic turning points of the composite index of coincident indicators. This is done by estimating a probit model with all the chosen leading indicators simultaneously as explanatory variables. Their results indicate that the model could accurately forecast business cycle turning points in the 1980s. However, in the 1990s, the model displays a diminished capacity to forecast the turning points. The present study differs from their study in several ways. Instead of evaluating the joint performance of the leading indicators, we are evaluating the performance of the leading indicators individually to find the individual leading indicator that most accurately predicts business cycle turning points. Methodologically, we use the pseudo $\mathrm{R}^{2}$ developed by Estrella (1998) for models with dichotonomous dependent variables to evaluate the models, unlike their qualitative evaluation.

\section{THE TECHNIQUES}

\subsection{The Probit model}

Several authors have used probit models to model business cycle turning points (see e.g. Estrella and Hardouvelis, 1991; Dueker, 1997; Dotsey, 1998; Estrella and Mishkin, 1998; Bernard and Gerlach, 1996). The probit form is dictated by the fact that the variable being predicted takes on only two possible values - 
whether the economy is in a recession or not. The model is defined in reference to a theoretical linear relationship of the form:

$$
\mathrm{Y}_{\mathrm{t}+\mathrm{k}}^{*}=\alpha+\beta * \mathrm{x}_{\mathrm{t}}+\varepsilon_{\mathrm{t}}
$$

where $Y_{t}^{*}$ is an unobserved variable that determines the occurrence of a recession at time $\mathrm{t}, \mathrm{k}$ is the length of the forecast horizon, $\varepsilon_{\mathrm{t}}$ is a normally distributed error term, and $x_{t}$ the value of the explanatory variable at time $t$. The parameters $\alpha$ and $\beta$ are estimated with maximum likelihood. The observable recession indicator $R_{t}$ is related to this model by

$R_{t}=1$ if $Y_{t}^{*}>0$, and 0 otherwise.

The form of the estimated equation is

$\mathrm{P}\left(\mathrm{R}_{\mathrm{t}+\mathrm{k}}=1\right)=\mathrm{F}\left(\alpha+\beta^{*} \mathrm{x}_{\mathrm{t}}\right)$

where $\mathrm{F}$ is the cumulative normal distribution function.

The model is estimated by maximum likelihood. The recession indicator is obtained from the South African Reserve Bank, that is, $R_{t}=1$ if they classify the economy to be in a downward phase at time $t$, and 0 otherwise (see Table 1).

Table 1 Business cycle phases according to SARB since 1978

\begin{tabular}{||llll||}
\hline Upward phase & \multicolumn{3}{|c||}{ Downward phase } \\
\hline January 1978 & August 1981 & September 1981 & March 1983 \\
April 1983 & June 1984 & July 1984 & March 1986 \\
April 1986 & February 1989 & March 1989 & May 1993 \\
June 1993 & November 1996 & December 1996 & August 1999 \\
\hline \hline
\end{tabular}

\subsection{Pseudo- $\mathrm{R}^{2}$ for models with dichotonomous dependent variables}

Estrella (1998) developed a pseudo $\mathrm{R}^{2}$ that measure the goodness of fit in the context of a dichotomous dependent variable, which corresponds intuitively to the widely used coefficient of determination in a standard linear regression. Let the unconstrained maximum value of the likelihood function $\mathrm{L}$ be $\mathrm{L}_{\mathrm{U}}$, and its maximum value under the constraint that all coefficients are zero except for the constant as $\mathrm{L}_{\mathrm{C}}$. Denote the number of observations with $\mathrm{n}$. Then 
Pseudo $R^{2}=1-\left(\frac{\log \left(L_{U}\right)}{\log \left(L_{c}\right)}\right)^{-(2 / n) \log \left(L_{c}\right)}$.

The form of this function ensures that the values 0 and 1 correspond to "no fit" and "perfect fit" respectively, and that intermediate values have roughly the same interpretations as their analogues in the linear case.

Estrella's pseudo $\mathrm{R}^{2}$ is easy to apply. First, a probit model with only a constant as explanatory variable is estimated to calculate the maximum value of the restricted likelihood function $\left(\mathrm{L}_{\mathrm{C}}\right)$. Next, a probit model is estimated with the appropriate number of months ahead of the explanatory variable in order to calculate the unconstrained maximum likelihood $\left(\mathrm{L}_{U}\right)$. These two values are simply substituted into the formula of the pseudo $\mathrm{R}^{2}$. These $\mathrm{R}^{2}$-values are comparable and the model with the highest is the best model.

\section{INDICATORS EXAMINED AND DATA USED}

The primary focus of this paper is to compare the performance of different individual economic indicators in predicting business cycle turning points. Variables such as interest rates, international indicators, stock price indices and monetary aggregates are examined. The performance of these individual indicators will also be compared with the performance of the composite index of leading indicators compiled by the South African Reserve Bank. Most of the components of the composite index of leading indicators, for example share prices, money supply and the number of residential building plans passed, are also tested individually.

It should be kept in mind that the objective of the composite index of leading indicators is not solely to predict the turning points of the business cycle, but also to provide information regarding the levels of economic growth. It is therefore possible that an individual indicator, even a single component of the composite index, can outperform the index in terms of predicting turning points, even though the index itself is better at predicting the course of the business cycle. All the variables included in the analysis are well-established leading economic indicators, and the selection is based on that of Estrella and Mishkin (1998).

Financial variables such as different stock indices are commonly associated with the expectations of future economic events. According to the dividend model of Williams (1938), stock prices are the sum of expected future dividends discounted by future interest or discounting rates. This means that stock indices 
are forward-looking indicators of expected economic conditions and interest rates and should therefore be good leading economic indicators. Following Estrella and Mishkin (1998), the overall stock index as well as the financial, mining and commercial share indices and the price-earnings ratio were included in the analysis.

Two monetary policy variables, namely short-term interest rates and (different definitions of) money supply, were also included in the study. In addition, the long-term interest rate was included since it should reflect expected future shortterm interest rates according to the expectations hypothesis.

Recently the yield spread, defined as the difference between the long-term interest rate and the short-term interest rate, as leading indicator has received considerable attention in the literature (see e.g Estrella \& Hardouvelis (1991), Bernard \& Gerlach (1996), and Estrella \& Mishkin (1998)). Intuitively, assume that the country is currently enjoying high growth, so that there is a general agreement among investors that the country is heading for a slow-down or recession in the future. Consumers want to hedge against the recession, and therefore purchase financial instruments (e.g. long-term bonds) that will deliver pay-offs during the economic slowdown. The increased demand for long-term bonds causes an increase in the price of long-term bonds, in other words a decrease in the yield on long-term bonds. In order to finance these purchases, investors sell their shorter-term assets, which results in a decline in the price of short-term assets and an increase in the yield on short-term assets. In other words, if a recession is expected, long-term interest rates will fall and short-term interest rates will rise. Consequently, prior to the recession, the slope of the term structure of interest rates will become flat (or even inverted), which means that the yield spread declines. Similarly, long-term interest rates rises while shortterm interest rates falls when an expansion is expected, so that an upwardsloping yield curve predicts an expansion.

South Africa is a small, open economy and is therefore extremely vulnerable to changes in economies in the rest of the world, especially those of our trading partners and the dominant economies such as the US and Europe. This is increasingly the case since the early 1990s when South Africa re-entered the international economy after economic sanctions were lifted, while globalization generally increased economic interdependence amongst countries. This motivated the inclusion of the composite index of leading indicators of South Africa's trading partners as well as that of the US. Since South Africa is such an open economy, exchange rates have a significant influence on the performance of the economy, and since it takes time for changes in the exchange rate to affect domestic prices and hence economic growth, the exchange rate could be a leading indicator of the economy, especially when using higher frequency data. 
Lastly, some macroeconomic indicators such as building plans passed and unfilled and new manufacturing orders are included on the basis that they reflect the expectations of economic agents.

\section{Table 2 List of variables}

\begin{tabular}{|c|c|c|}
\hline Series & Description & Transformation used \\
\hline & Interest Rates & \\
\hline $\mathrm{RS}(\mathrm{RSS})$ & $\begin{array}{l}\text { Short-term nominal (real) interest rate } \\
\text { (3 month BA rate) }\end{array}$ & \\
\hline RL (RRL) & $\begin{array}{l}\text { Long-term nominal (real) interest rate } \\
\text { (10-vear government bond vield) }\end{array}$ & \\
\hline SPR & $\begin{array}{l}\text { Yield spread, defined as the long-term } \\
\text { minus the short-term interest rate (RL- } \\
\text { RS) } \\
\text { Monetary Aggregates }\end{array}$ & \\
\hline M3 (RM3) & Nominal (real) M3 money supply & Year on year growth \\
\hline M2 (RM2) & Nominal (real) M2 money supply & Year on year growth \\
\hline M1 (RM1) & $\begin{array}{l}\text { Nominal (real) M1 money supply } \\
\text { Stock Prices }\end{array}$ & Year on year growth \\
\hline JSE & All share index & Year on year growth \\
\hline FS & Financial shares index & Year on year growth \\
\hline MS & Mining shares index & Year on year growth \\
\hline $\mathrm{CS}$ & Commercial shares index & Year on year growth \\
\hline PE & $\begin{array}{l}\text { Price-earnings ratio } \\
\text { International Indicators }\end{array}$ & \\
\hline NEE & Nominal effective exchange rate & Year on year growth \\
\hline REE & Real effective exchange rate & Year on year growth \\
\hline $\mathrm{R} \$$ & Rand-US\$ exchange rate & Year on year growth \\
\hline US & $\begin{array}{l}\text { US composite index of leading } \\
\text { indicators }\end{array}$ & Year on year growth \\
\hline TR & $\begin{array}{l}\text { Composite index of leading indicators } \\
\text { of trading partners } \\
\text { Macroeconomic indicators }\end{array}$ & Year on year growth \\
\hline $\mathrm{BP}$ & Building plans passed & \\
\hline INF & CPI inflation & \\
\hline $\mathrm{UO}$ & Manufacturing, unfilled orders & Year on year growth \\
\hline NO & Manufacturing, new orders & Year on year growth \\
\hline CIL & Composite index of leading indicators & Year on year growth \\
\hline
\end{tabular}




\section{EMPIRICAL ANALYSIS}

Monthly data for the period March 1978 to March 2001 was used in the empirical analysis. Forecasts for 1 to 18 months ahead, in other words up to a year and a half, were considered.

\subsection{Performance of individual leading indicators}

The pseudo $\mathrm{R}^{2}$ developed by Estrella (1998) (see section 3.2) is used to compare the forecast performance of each individual leading indicator in forecasting business cycle turning points for 1 to 18 months ahead. The pseudo $\mathrm{R}^{2}$ values of the models are given in Table 3. Three different transformations of each variable were tested, namely the series in levels, in first differenced form and the year on year growth in the series. Only the transformation of each series that performed best is reported, the rest of the results are omitted for brevity and are available from the author upon request. The transformation of each series that was used is reported in Table 2 . The highest $\mathrm{R}^{2}$ value of each indicator is indicated in bold print.

Table 3 Pseudo $\mathbf{R}^{2}$-values of leading indicators

\begin{tabular}{||lllllllllll||}
\hline $\begin{array}{l}\text { Lead } \\
\text { month }\end{array}$ & SPR & RS & RL & RRS & M3 & RM3 & $R R L$ & INF & US & R\$ \\
\hline 1 & 0.409 & 0.517 & 0.158 & 0.285 & 0.008 & 0.083 & 0.075 & 0.016 & $\mathbf{0 . 1 4 1}$ & 0.231 \\
2 & 0.478 & 0.583 & 0.160 & 0.314 & 0.010 & 0.077 & 0.075 & 0.016 & 0.131 & 0.266 \\
3 & 0.540 & 0.641 & $\mathbf{0 . 1 6 3}$ & 0.341 & 0.018 & 0.074 & 0.075 & 0.016 & 0.119 & $\mathbf{0 . 2 8 7}$ \\
4 & 0.587 & 0.684 & $\mathbf{0 . 1 6 3}$ & 0.362 & 0.033 & 0.079 & 0.076 & 0.017 & 0.108 & 0.283 \\
5 & 0.618 & 0.705 & 0.162 & 0.372 & 0.059 & 0.091 & $\mathbf{0 . 0 9 7}$ & $\mathbf{0 . 0 1 8}$ & 0.099 & 0.268 \\
6 & 0.635 & 0.714 & 0.160 & $\mathbf{0 . 3 7 3}$ & 0.087 & 0.108 & 0.075 & $\mathbf{0 . 0 1 8}$ & 0.093 & 0.253 \\
7 & $\mathbf{0 . 6 4 3}$ & $\mathbf{0 . 7 2 0}$ & 0.160 & 0.364 & 0.122 & 0.131 & 0.071 & 0.017 & 0.089 & 0.234 \\
8 & 0.627 & 0.691 & 0.160 & 0.342 & 0.155 & 0.158 & 0.065 & 0.016 & 0.082 & 0.214 \\
9 & 0.578 & 0.622 & 0.152 & 0.307 & 0.194 & 0.190 & 0.059 & 0.016 & 0.076 & 0.196 \\
10 & 0.536 & 0.562 & 0.144 & 0.275 & 0.238 & 0.230 & 0.053 & 0.015 & 0.071 & 0.173 \\
11 & 0.483 & 0.492 & 0.132 & 0.238 & 0.283 & 0.270 & 0.045 & 0.015 & 0.068 & 0.152 \\
12 & 0.424 & 0.416 & 0.118 & 0.198 & 0.340 & 0.324 & 0.036 & 0.014 & 0.066 & 0.134 \\
13 & 0.358 & 0.342 & 0.106 & 0.157 & 0.383 & 0.368 & 0.028 & 0.014 & 0.068 & 0.120 \\
14 & 0.297 & 0.279 & 0.096 & 0.121 & 0.421 & 0.406 & 0.022 & 0.013 & 0.071 & 0.116 \\
15 & 0.245 & 0.226 & 0.090 & 0.089 & 0.452 & 0.439 & 0.015 & 0.012 & 0.074 & 0.120 \\
16 & 0.203 & 0.190 & 0.088 & 0.061 & $\mathbf{0 . 4 6 6}$ & 0.398 & 0.010 & 0.010 & 0.078 & 0.131 \\
17 & 0.172 & 0.162 & 0.087 & 0.041 & 0.452 & 0.446 & 0.006 & 0.009 & 0.082 & 0.148 \\
18 & 0.150 & 0.141 & 0.087 & 0.024 & 0.455 & $\mathbf{0 . 4 5 0}$ & 0.005 & 0.008 & 0.088 & 0.170 \\
\hline
\end{tabular}


Table 3 continued

\begin{tabular}{||lllllllllll||}
\hline $\begin{array}{l}\text { Lead } \\
\text { month }\end{array}$ & BP & CIL & PE & UO & NEE & CS & NO & MS & FS & TR \\
\hline 1 & 0.037 & 0.644 & 0.435 & $\mathbf{0 . 1 7 3}$ & 0.132 & 0.118 & $\mathbf{0 . 3 4 0}$ & 0.228 & 0.153 & 0.017 \\
3 & 0.052 & 0.691 & 0.450 & 0.139 & 0.137 & 0.146 & 0.274 & 0.258 & 0.168 & 0.023 \\
4 & 0.064 & $\mathbf{0 . 7 1 3}$ & 0.462 & 0.114 & 0.139 & $\mathbf{0 . 1 5 9}$ & 0.229 & $\mathbf{0 . 2 8 5}$ & $\mathbf{0 . 1 8 0}$ & 0.028 \\
5 & 0.084 & 0.705 & 0.469 & 0.099 & 0.134 & 0.160 & 0.228 & 0.272 & 0.159 & 0.031 \\
6 & 0.113 & 0.665 & $\mathbf{0 . 4 7 0}$ & 0.083 & 0.127 & 0.162 & 0.187 & 0.271 & 0.156 & 0.033 \\
7 & 0.120 & 0.618 & 0.463 & 0.074 & 0.118 & 0.164 & 0.152 & 0.283 & 0.158 & 0.037 \\
8 & 0.143 & 0.553 & 0.448 & 0.070 & 0.108 & 0.153 & 0.140 & 0.268 & 0.145 & 0.040 \\
9 & 0.174 & 0.478 & 0.428 & 0.064 & 0.100 & 0.129 & 0.116 & 0.254 & 0.131 & 0.043 \\
10 & 0.192 & 0.393 & 0.410 & 0.064 & 0.096 & 0.104 & 0.102 & 0.218 & 0.110 & 0.047 \\
11 & 0.227 & 0.310 & 0.391 & 0.065 & 0.096 & 0.076 & 0.084 & 0.182 & 0.084 & 0.052 \\
12 & 0.258 & 0.234 & 0.373 & 0.068 & 0.101 & 0.048 & 0.069 & 0.144 & 0.058 & 0.058 \\
13 & 0.269 & 0.167 & 0.359 & 0.074 & 0.111 & 0.028 & 0.067 & 0.106 & 0.036 & 0.065 \\
14 & 0.287 & 0.114 & 0.348 & 0.078 & 0.125 & 0.014 & 0.067 & 0.076 & 0.019 & 0.073 \\
15 & 0.301 & 0.072 & 0.341 & 0.082 & 0.145 & 0.009 & 0.069 & 0.056 & 0.012 & 0.079 \\
16 & $\mathbf{0 . 3 0 2}$ & 0.022 & 0.337 & 0.086 & 0.168 & 0.002 & 0.031 & 0.036 & 0.009 & 0.084 \\
17 & 0.294 & 0.012 & 0.341 & 0.088 & 0.191 & 0.009 & 0.080 & 0.029 & 0.008 & 0.088 \\
18 & 0.295 & 0.008 & 0.337 & 0.093 & 0.216 & 0.010 & 0.085 & 0.021 & 0.009 & 0.091 \\
\hline
\end{tabular}

From the results in Table 3 it is clear that the short-term interest rate leading 7 months has the highest $\mathrm{R}^{2}$ value, followed by the year on year change in the Reserve Bank's composite index of leading indicators leading 3 months, and the yield spread leading 7 months. These three models explain 72.0404 per cent, 71.2595 per cent and 64.3182 per cent respectively of the variation in the dependent variable. However, the composite index of leading indicators is only available with a four to five month lag, and is subject to revision. In other words, the optimal number of months ahead is not available in time for forecasting. The months that are available yield lower $\mathrm{R}^{2}$ values than the yield spread, which should be kept in mind when using these indicators for forecasting purposes. Both the short-term interest rate and the yield spread are immediately available and not subject to revision, and both of them has the same optimal forecasting period.

\subsection{Probit models}

Table 4 presents the results of the probit models with the composite index of leading indicators, the short-term interest rate and the yield spread. Each of the models was estimated with only one explanatory variable and a constant, with the leading time chosen on the basis of the pseudo $\mathrm{R}^{2}$ values in Table 3. The 
parameters were estimated with maximum likelihood and their standard errors are reported below in parenthesis.

Table 4 Probit models

\begin{tabular}{||l|l|l|l|l||}
\hline $\begin{array}{l}\text { Explanatory } \\
\text { variable }\end{array}$ & $\begin{array}{l}\text { Lead } \\
\text { (months) }\end{array}$ & Constant & Coefficient & Pseudo R $^{2}$ \\
\hline & & & & \\
\hline SPR & 7 & 0.246 & -0.493 & $64 \%$ \\
\hline & & $(0.107)$ & $(0.050)$ & \\
\hline RS & 7 & -7.425 & 0.519 & $72 \%$ \\
\hline & & $(0.818)$ & $(0.056)$ & \\
\hline CIL & 3 & 0.361 & -0.273 & $71 \%$ \\
\hline & & $(0.119)$ & $(0.030)$ & \\
\hline
\end{tabular}

The results in Table 4 are interpreted as follows:

$\mathrm{P}\left(\mathrm{R}_{\mathrm{t}+7}=1\right)=\mathrm{F}\left(0.246-0.493 * \mathrm{SPR}_{\mathrm{t}}\right)$

$\mathrm{P}\left(\mathrm{R}_{\mathrm{t}+7}=1\right)=\mathrm{F}\left(-7.425+0.519 * \mathrm{RS}_{\mathrm{t}}\right)$

$\mathrm{P}\left(\mathrm{R}_{\mathrm{t}+3}=1\right)=\mathrm{F}\left(0.361-0.273^{*} \mathrm{CIL}_{\mathrm{t}}\right)$

where $\mathrm{F}$ is the cumulative normal distribution, $\mathrm{R}_{\mathrm{t}}$ is a dummy variable that takes on the values one if the economy is in a recession in period $t$, and $P\left(R_{t+i}=1\right)$ is the probability that the economy is in a recession in period $t+i$.

These results are consistent with a priori expectations. According to the results in equation 7 there is a negative relationship between the composite index of leading indicators and the probability of a recession, which means that an increase in the composite index of leading indicators predicts a decline in the probability of a future recession. In other words, an increase in the composite index of leading indicators indicates a higher probability of an economic upswing, which is consistent with the construction of the composite index of leading indicators. Equation 6 indicates that an increase (decrease) in the shortterm interest rate is associated with an increase (decrease) in the probability of a future recession. In other words, lower interest rates stimulate the economy since it increases (decreases) the likelihood of a future economic upswing (downswing). According to equation 5 there is a negative relationship between the interest rate spread and the probability of a recession in future, which means that increases in the interest rate spread lowers the probability of a future recession. This is consistent with the theoretical relationship between the interest rate spread and economic activity, according to which the interest rate spread will decline prior to a recession (see section 4). 
Given these formulas, the probability of a recession associated with certain values of the explanatory variables can be calculated easily. For example, a short-term interest rate of 13 per cent in a certain period indicates that the probability that the economy will be in a recession 7 periods ahead is 25 per cent. The recession probabilities of some of the possible values of the explanatory variables are given in Table 5 . The last row in Table 5 presents the values of the three economic indicators associated with the probability of a recession of exactly 50 per cent. In other words, an interest rate spread below 0.499 per cent and a year-on-year growth in the composite index of leading indicators below 13.22 per cent predicts that the economy is more likely to be in a recession than an expansion seven or three months ahead respectively. On the other hand, a short-term interest rate above 14.306 per cent predicts that the economy is more likely to be in a recession than an expansion seven months ahead.

Table 5 Probability of a recession two quarters ahead as a function of the short-term interest rate, the interest rate spread and the composite index of leading indicators

\begin{tabular}{||l|l|l|l|l|l||}
\hline \hline $\mathbf{S P R}_{\mathbf{t}}$ & $\mathbf{P}\left(\mathbf{R}_{\mathbf{t + 7}}=\mathbf{1}\right)$ & $\mathbf{R S}_{\mathbf{t}}$ & $\mathbf{P}\left(\mathbf{R}_{\mathbf{t + 7}}=\mathbf{1}\right)$ & $\mathbf{C L I}_{\mathbf{t}}$ & $\mathbf{P}\left(\mathbf{R}_{\mathbf{t + 3}}=\mathbf{1}\right)$ \\
\hline-6 & 1.00 & 4.00 & 0.00 & -13.00 & 1.00 \\
\hline-5 & 1.00 & 5.50 & 0.00 & -10.00 & 1.00 \\
\hline-4 & 0.99 & 7.00 & 0.00 & -7.00 & 0.99 \\
\hline-3 & 0.96 & 8.50 & 0.00 & -4.00 & 0.93 \\
\hline-2 & 0.89 & 10.00 & 0.01 & -1.00 & 0.74 \\
\hline-1 & 0.77 & 11.50 & 0.07 & 2.00 & 0.43 \\
\hline 0 & 0.60 & 13.00 & 0.25 & 5.00 & 0.16 \\
\hline 1 & 0.40 & 14.50 & 0.54 & 8.00 & 0.03 \\
\hline 2 & 0.23 & 16.00 & 0.81 & 11.00 & 0.00 \\
\hline 3 & 0.11 & 17.50 & 0.95 & 14.00 & 0.00 \\
\hline 4 & 0.04 & 19.00 & 0.99 & 17.00 & 0.00 \\
\hline 5 & 0.01 & 20.50 & 1.00 & 20.00 & 0.00 \\
\hline 6 & 0.00 & 22.00 & 1.00 & 26.00 & 0.00 \\
\hline 0.499 & 0.5 & 14.306 & 0.5 & 13.322 & 0.5 \\
\hline \hline
\end{tabular}

Figures 1 to 3 plot the estimated probability of a recession derived from each model. The shaded areas denote periods of actual recessions as classified by the South African Reserve Bank, and the lines indicate the probability that the economy is in a recession in that period. 


\section{Figure 1 Recession probability predicted by short-term interest rate}

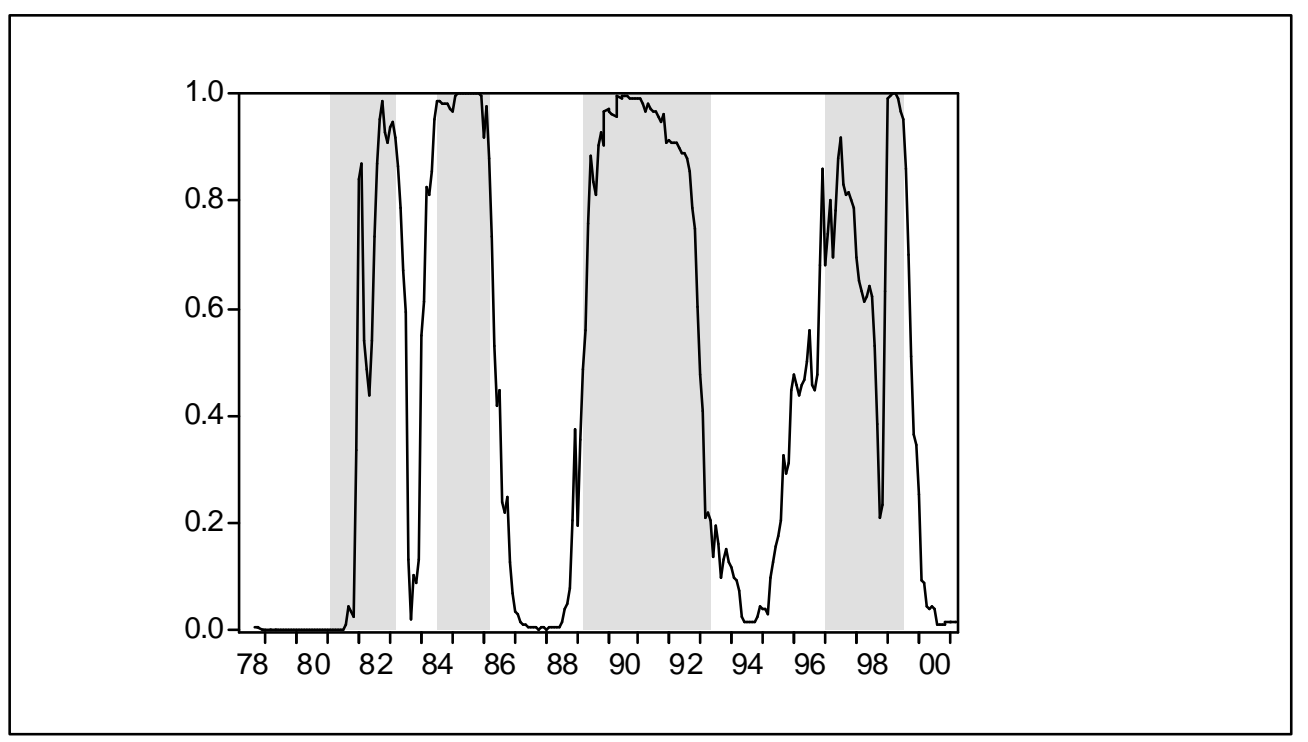

Figure 2 Recession probability predicted by interest rate spread

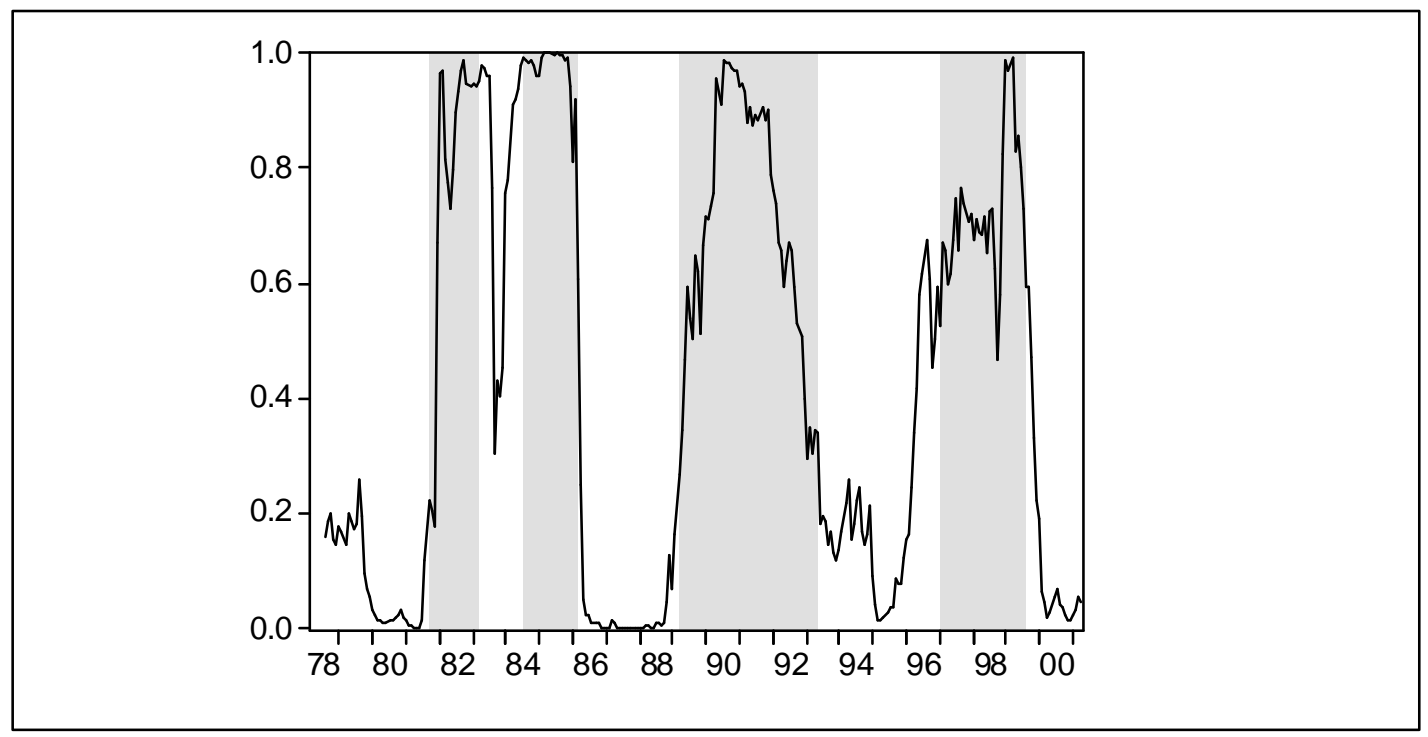

The lines in figures 1 to 3 represent the probability that the economy will be in a recession in a particular period as calculated by the three different probit models using the short-term interest rate, the interest rate spread and the composite index of leading indicators respectively as explanatory variables. If the probability of a recession is above (below) 50 per cent, it will be regarded as a predicted recession (expansion). These predicted recessions can be compared with the official dates of the South African Reserve Bank presented by the shaded areas. For example, the composite index of leading indicators predicted a recession early in 1981 (when the probability of a recession exceeded 50 per cent) compared with the actual recession that occurred at the end of 1981. 


\section{Figure 3 Recession probability predicted by composite index of leading indicators}

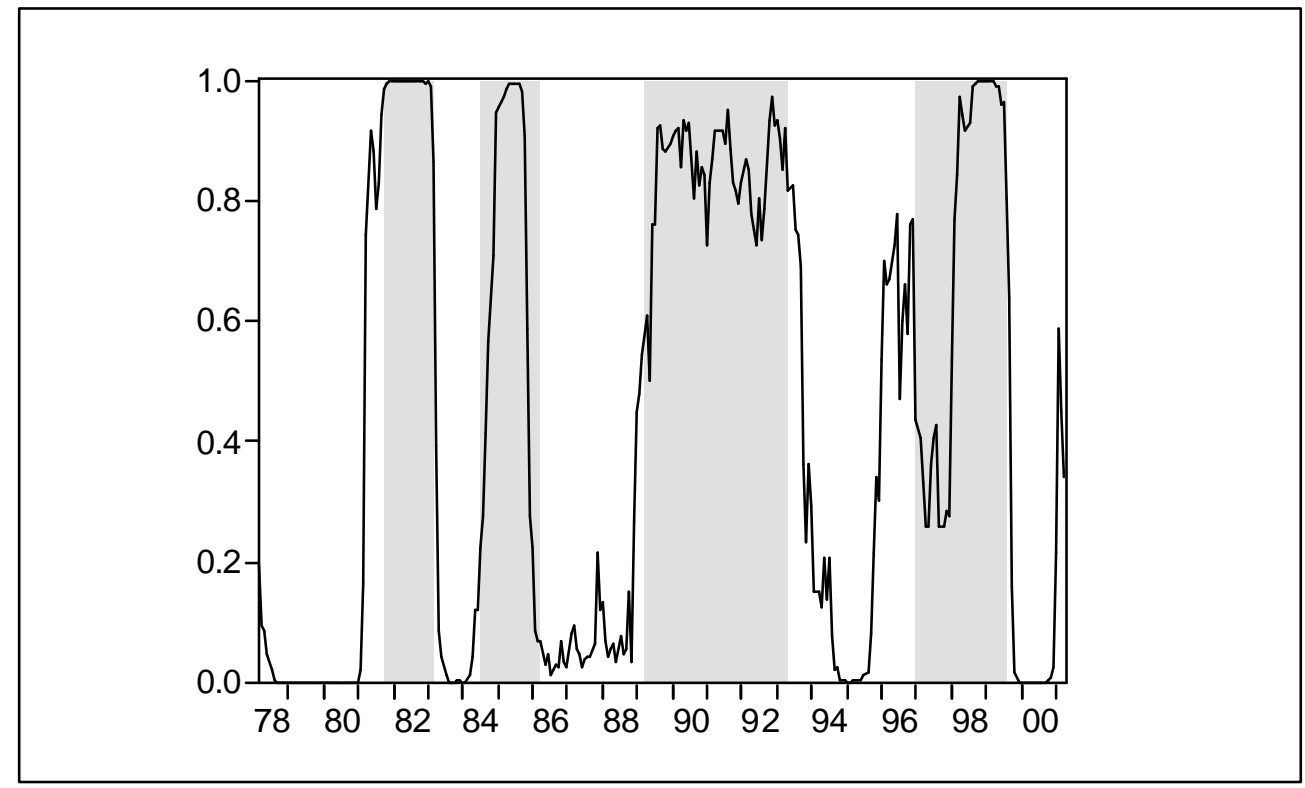

None of the three models missed any cycle. However, the model with the composite index of leading indicators gave a false signal of a downswing in January 1996 and an upswing in January 1997. In addition, the model with the composite index of leading indicators gave a false signal of a downswing in January 2001. In general, all three models performed fairly well. The models with the short-term interest rate and the yield spread seems to have performed somewhat worse at the beginning of the sample with the 1983-1984 upswing, while they performed quite well for the rest of the period. On the other hand, the performance of the model with the composite index of leading indicators seemed to have deteriorated over the sample period.

The deteriorating performance of the composite index and the improving performance of the interest rate models might be the result of important structural change in the economy. And, unlike the composite index, neither of the interest rate models gave any false signals. In addition, the optimal forecast period of the interest rate models are both seven months compared to three months in the case of the composite index, and the interest rate variables are available in time and are not revised. Therefore, both interest rate models are preferred to the model with the composite index of leading indicators. In general, the model with the short-term interest rate performed slightly better than the model with the yield spread. 


\section{CONCLUSION}

The objective of this study was to find the individual leading indicator that is best at predicting turning points of the South African business cycle. The pseudo $\mathrm{R}^{2}$ indicated that the three best individual indicators are the short-term interest rate, the yield spread and the composite index of leading indicators compiled by the South African Reserve Bank. They led the turning points with seven, seven and three months respectively. A close inspection of the probit models of these three individual indicators as explanatory variables indicated that the two interest rate models are preferred to the model with the composite index. Data availability is better in the case of the interest rates, and unlike the composite index, neither of them gave any false signals. In general, their performance seemed to have improved over the course of the sample period, while the performance of the composite index seemed to have deteriorated over the course of the sample period. Performance at the end of the sample is obviously more important for forecasting purposes. In addition, these trends might also be reflecting an underlying structural change in the economy, which makes the interest rate models even more desirable since it seems as if they are better at predicting the new structure than the composite index.

\section{REFERENCES}

1 BERNARD, H. \& GERLACH, S. (1996) "Does the term structure predict recession? The international evidence", Bank for International Settlements Working Paper No 37.

2 BURNS, A.F. \& MITCHELL, W.C. (1946) Measuring Business Cycles. New York: National Bureau of Economic Research.

3 COOK, M.P. \& SMIT, E. V.D. M. (2001) "Forecasting cyclical turning points by means of a probabilistic approach: Some South African evidence", Journal for Studies in Economics and Econometrics, 25(3): 75104.

4 DOTSEY, M. (1998) "The predictive content of the interest rate term spread for future economic growth", Federal Reserve Bank of Richmond Economic Quarterly, 84: 31-51.

5 DUEKER, M.J. (1997) "Strengthening the case for the yield curve as a predictor of US recessions", Federal Reserve Bank of St. Louis Review, 79: 41-51.

6 ESTRELLA, A. (1998) "A new measure of fit for equations with dichotomous dependent variables", Journal of Business and Economic Statistics, 16(2): 198-205.

7 ESTRELLA, A. \& HARDOUVELIS, G.A. (1991) "The term structure as a predictor of real economic activity" The Journal of Finance, 46: 555-75. 
8 ESTRELLA, A., \& MISHKIN, F.S. (1998) "Predicting U.S. recessions: financial variables as leading indicators", The Review of Economics and Statistics, 80: 45-60.

9 IVANOVA, D., LAHIRI, K. \& SEITZ, F. (2000) "Interest rate spreads as predictors of German inflation and business cycles", International Journal of Forecasting, 16(1): 39-58.

10 MISHKIN, F.S. (1998) The Economics of Money, Banking, and Financial Markets, Addison-Wesley.

11 NEL, H. (1996) "The term structure of interest rates and economic activity in South Africa", The South African Journal of Economics, 64(3): 161-74.

12 WILLIAMS, J.B. (1938) The Theory of Investment Value, Massachusetts: Cambridge Press. 